\title{
Preparation of Silicon-Carbon-Graphene Composites and their Application to Lithium Ion Secondary Battery
}

\author{
Sun Kyung Kim¹, Chan Mi Kim, Hankwon Chang ${ }^{1,2}$, Hee Dong Jang ${ }^{1,2 *}$ \\ ${ }^{1}$ Resources Utilization Research Center, Korea Institute of Geoscience \& Mineral Resources, \\ Daejeon 34132, Korea \\ ${ }^{2}$ Department of Nanomaterials Science and Engineering, University of Science \& Technology, \\ Daejeon 34113, Korea
}

\section{ABSTRACT}

Recently, high electrochemical performance anode materials for lithium ion secondary batteries are of interest. Here, we present silicon-carbon-graphene (Si-C-GR) composites for high performance anode materials of lithium ion secondary battery (LIB). Aerosol process and heat-treatment were employed to prepare the Si-C-GR composites using a colloidal mixture of silicon, glucose, and graphene oxide (GO) precursor. Fabrication of the Si-C-GR composites was composed of two stages. The first stage was formation of Si-glucose-GO composites by co-assembly of Si and GO while the sprayed droplets of the colloidal mixture went through the pre-heated aerosol reactor, and the second stage was carbonization of glucose and thermal reduction of GO by heat treatment. Morphology of as-fabricated Si-C-GR composites was generally the shape of a crumpled paper ball and the Si particles were well wrapped in carbon and graphene. The effects of the size of the silicon particles in Si-C-GR composites on the material properties including the morphology and crystal structure were investigated. Silicon particles ranged from $50 \mathrm{~nm}$ to $1 \mu \mathrm{m}$ in average diameter were employed while concentration of silicon, graphene oxide and glucose was fixed in the aerosol precursor. The size range of composites was about from 2.2 to $2.9 \mu \mathrm{m}$. The composites including silicon particles larger than $200 \mathrm{~nm}$ in size exhibited higher performance as LIB anodes such as capacity and coulombic efficiency than silicon particles less than $100 \mathrm{~nm}$, which were about $1500 \mathrm{mAh} \mathrm{g}^{-1}$ at 100 cycles in capacity and 99\% in coulombic efficiency, respectively.

This article is an English version of "Preparation of SiliconCarbon-Graphene Composites and their Application to Lithium Ion Secondary Battery" published in the Particle and Aerosol Research in December 2019.

Publisher:

Taiwan Association for Aerosol Research

ISSN: $1680-8584$ print

ISSN: 2071-1409 online

Copyright: The Author's institution. This is an open access article distributed under the terms of the Creative Commons Attribution License (CC BY 4.0), which permits unrestricted use, distribution, and reproduction in any medium, provided the original author and source are cited.

Keywords: Aerosol process, Lithium ion battery (LIB), Anode materials, Silicon-carbon-graphene (Si-C-GR) composites

\section{INTRODUCTION}

Recently, lead-acid batteries, nickel cadmium batteries ( $\mathrm{Ni}-\mathrm{Cd}$ ), and nickel metal hydride batteries $(\mathrm{Ni}-\mathrm{MH})$ have been widely used as small secondary batteries. In view of the current trend of increasing development of portable wireless electronic products, it is necessary to develop secondary batteries with high energy density to miniaturize and improve these products. Among various secondary batteries, lithium ion batteries (LIBs) as secondary batteries exhibit relatively high energy density and output in the energy storage field, and are receiving substantial attention due to their excellent cycle life and energy density (Tarascon et al., 2001).

Early LIBs that used lithium metal as anode materials were difficult to commercialize due to the deposition of lithium metal dendrites during charging/discharging, and the problem of stability and irreversibility inside the battery (Selis et al., 2018). Since then, graphite has been widely used as an anode material but it was necessary to find alternative anode materials with better capacity because of graphite's low theoretical capacity of $372 \mathrm{mAh} \mathrm{g}^{-1}$ (Zhang et al., 2015). Among possible materials, silicon was expected to play an important role in the secondary 
battery market due to its high theoretical capacity of $4200 \mathrm{mAh} \mathrm{g}^{-1}$, low discharge potential, and non-toxic properties (Ashuri et al., 2016).

However, despite the high theoretical capacity, when silicon was used as an anode material for a LIB, about $400 \%$ of volume expansion occurred during the insertion and desorption of lithium ions in the electrode, thereby destroying the active materials (Xiao et al., 2010). These problems created an additionally formed a new solid electrolyte interphase (SEI), high resistance and low electrical conductivity, which made it difficult to commercialize (Oumellal et al., 2011; Beaulieu et al., 2001). To solve these problems, several researchers actively conducted research using various silicon particles such as silicon nano particles (Szczech et al., 2011; Kasavajjula et al., 2007) and silicon nanowires (Chan et al., 2010; Cui et al., 2009), silicon nanotubes (Park et al., 2009), hollow silicons (Yao et al., 2011), and porous silicons (Bao et al., 2007).

However, the production of nano-sized silicon particles involved an expensive and complex process, and it was also noted that the electrochemical performance of a silica cell was rapidly degraded by the formation of an unstable SEI. Therefore, composite materials have emerged for a LIB anode electrode material by compounding silicon and a carbon-based material, which is capable of accommodating a large volume expansion without direct contact between the silicon particle surface and the electrolyte.

Potential carbon materials used in silicon-carbon composites to improve the performance of LIBs are typically graphene, carbon nanotubes, activated carbon, etc., which are attracting attention as energy storage materials due to their excellent electrical and thermal conductivity (Kang et al., 2013; Yen et al., 2014). When this carbon-based material is mixed with silicon, it helps to buffer the large volume change of silicon, and for this reason, the silicon-carbon-based composites have shown improved electrochemical performance in previous studies. For example, Kim et al. (2019) prepared carbon and graphene with silicon nanoparticles in a liquid phase reaction in order to prevent direct silicon exposure to the electrolyte and increase the electrical conductivity of carbon materials. As a result, such composites have shown a high capacity value and a stable coulombic efficiency value even after 100 cycles (Kim et al., 2019). However, in the case of a liquid phase reaction, there was a disadvantage that the size or composition ratio of the synthesized complex was different due to the low uniformity of the product for each experimental batch. This had the effect of exhibiting the same reproducibility in the results of evaluation of LIBs. In addition, Fang et al. manufactured a silicon-carbon nanotube-graphene composite with a sponge shape through a hydrothermal reaction and applied it to a LIB. As a result, the sponge-like shape of the three-dimensional structure helped compensate for the volume expansion and exhibited a high capacity of about $1000 \mathrm{mAh} \mathrm{g}^{-1}$ after 100 cycles (Fang et al., 2018). In the case of a hydrothermal reaction, it takes a long time, 24 hours or more, and the experimental process is complicated. Therefore, research is necessary to develop composites for LIB anode electrode materials only require an easy and simple process and to increase the retention rate at an excellent capacity.

In this study, we prepared crumpled paper ball shaped silicon-carbon-graphene (Si-C-GR) composites with a double carbon coating layer from silicon in various sizes, and evaluated the characteristics of the composites for applying them as a potential anode electrode material for a LIB. In order to fabricate crumpled paper ball shaped Si-C-GR composites, we employed the aerosol self-assembly process which is known to have the advantage of being able to easily and quickly manufacture composites by one-step (Jang et al., 2013). The carbon addition to the silicon-graphene could accommodate a large increased volume of silicon between and on the surface of the silicon particles, and we expected to increase the characteristics of the LIB by preventing lamination in the GR sheets, thereby lowering the resistance (Kim et al., 2018a). We were employed aerosol spray drying and heat treatment processes to prepare the Si-C-GR composites from silicon, glucose and graphene oxide. We chose to use silicon of various sizes in order to investigate the effect on the electrochemical properties according to the size of silicon in the composite during charging and discharging. We performed FE-SEM, XRD, and Raman analysis to confirm the shape and crystal phase of the composite; and evaluated the electrochemical characteristics by applying the anode electrode material for a LIB. 

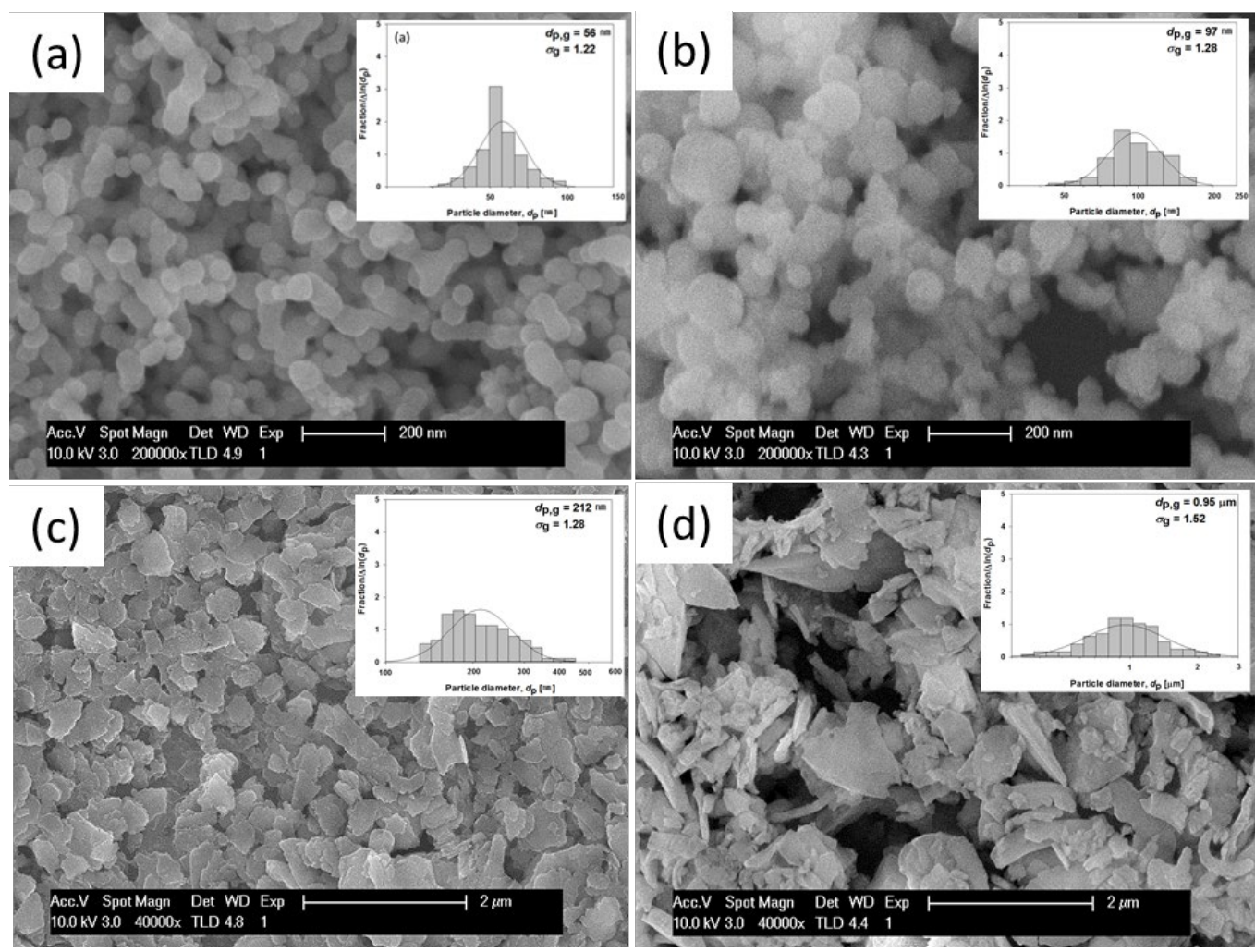

Fig. 1. FE-SEM images of the Si particles with different sizes of (a) $50 \mathrm{~nm}$, (b) $100 \mathrm{~nm}$, (c) $200 \mathrm{~nm}$ and (d) $1 \mu \mathrm{m}$.

\section{METHODS}

\subsection{Preparation of Silicon of Various Sizes}

To produce of the silicon-carbon-graphene (Si-C-GR) composites, we used four types of silicon particles with average particle sizes of $50 \mathrm{~nm}, 100 \mathrm{~nm}, 200 \mathrm{~nm}$, and $1 \mu \mathrm{m}$.

For the $50 \mathrm{~nm}$ and $100 \mathrm{~nm}$ silicon particles, we purchased commercial products from Alfa Aesar (98\%) and Sigma Aldrich (98\%), respectively. For $1 \mu \mathrm{m}$ silicon particles, we used silica sludge (99\%) generated in the solar cell wafer cutting process. The $200 \mathrm{~nm}$ silicon was prepared by grinding and dispersing using bead milling from $1 \mu \mathrm{m}$ silicon particles. To observed morphology of $50 \mathrm{~nm}$ and $100 \mathrm{~nm}$ silicon particles showed spherical shapes with uniform size distribution through FE-SEM analysis (Figs. 1(a-b)). The grind silicon of $200 \mathrm{~nm}$ showed generally uniform polygonal morphology (Fig. 1(c)). The $1 \mu \mathrm{m}$ silicon had a polygonal shape, and the size distribution showed non-uniform particle sizes (Fig. 1(d)).

\subsection{Preparation of Silicon-Carbon-Graphene (Si-C-GR) Composite}

Graphene oxide (GO) was prepared according to the Modified Hummers method (Cote et al., 2009), and glucose was used as a carbon source for the composites. To prepare a composite including carbon bilayers, we conducted an aerosol process using silicon, and a colloid of graphene oxide. At this time the concentration of silicon, glucose, and graphene oxide were fixed at 0.3 , $0.2 \mathrm{wt} \%$, and $0.2 \mathrm{wt} \%$, respectively, and the time silicon size was $50 \mathrm{~nm}, 100 \mathrm{~nm}, 200 \mathrm{~nm}$, and $1 \mu \mathrm{m}$ as variables. The reactor temperature of the aerosol process was $200^{\circ} \mathrm{C}$, and the carrier gas (Ar) was injected with a flow rate of $10 \mathrm{~L} \mathrm{~min}^{-1}$. Fig. 2 shows a process diagram for preparing the Si-C-GR composites. This process has the many advantages such as being able to easily and quickly mass produce three-dimensional composites with one continuous process (Jang et al., 2013). The aerosol-made Si-C-GO composite was transformed into a Si-C-GR composite by thermal reduction from graphene oxide to graphene and carbonization from glucose to carbon with heattreated at $800^{\circ} \mathrm{C}$ for 1 hour in $\mathrm{Ar}$ gas. 


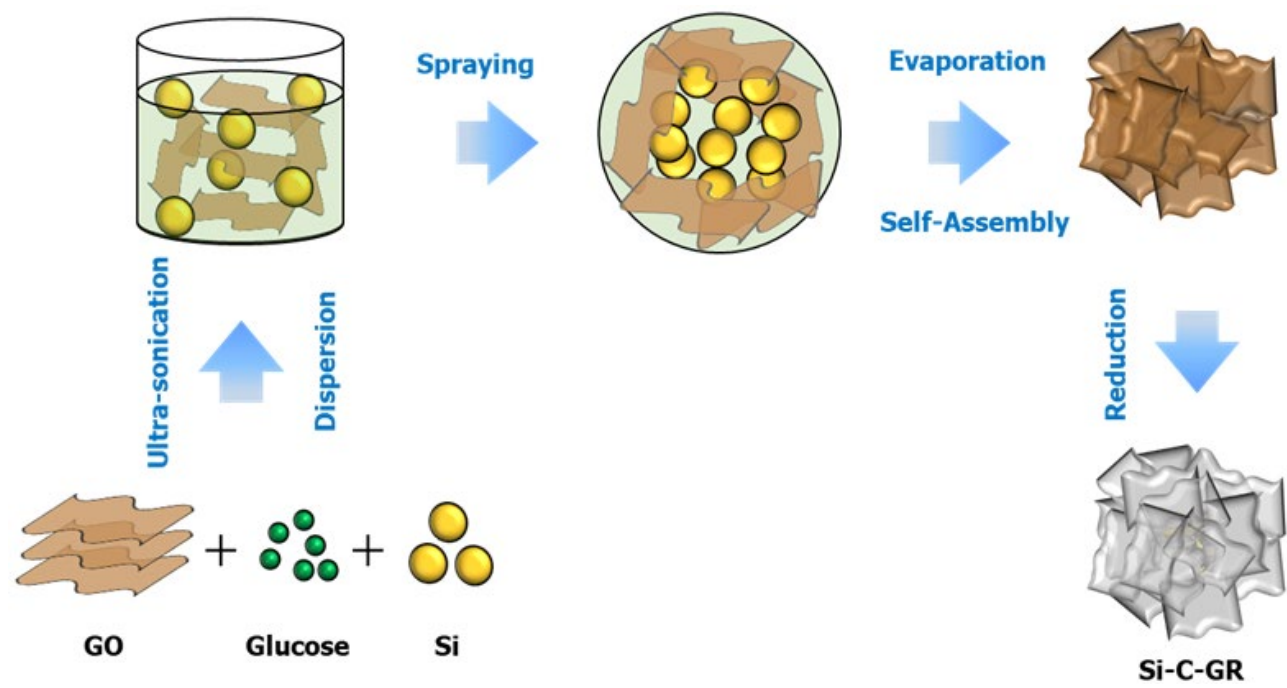

Fig. 2. Schematic illustration of the formation Si-C-GR composites via aerosol process and post heat treatment.

\subsection{Analysis}

The crystallinities, morphologies, and molecular species of the Si-C-GR composites were observed with X-ray diffractometry (XRD; RTP 300 RC, Rigaku, Japan), (FE-SEM; Sirion, FEI, USA), and Raman Spectroscopy (Raman; Dimension P1, Lamda solution Inc.). To evaluate the characteristics of LIBs composed of Si-C-GR composites, a charge/discharge test (Galvanostatic charge/discharge measurement, TOSCAT3000, Toyo) was performed using a CR2032 type coin cell. The reference electrode of the coin cell was lithium metal, and the coating slurry was a mixed electrode material: active material: binder (Solvay) $=80: 10: 10$ (wt\%). The measurement range was from 0.001 to $2.0 \mathrm{~V}\left(\mathrm{~V}\right.$ vs. $\mathrm{Li} / \mathrm{Li}^{+}$), and the current density was fixed at $0.2 \mathrm{~A} \mathrm{~g}^{-1}$. A solution of $1.0 \mathrm{M} \mathrm{LiPF}_{6}$ in ethyelene carbonate $(E C)$, dimethyl carbonate $(D M C)=1: 1$ (vol\%), was used as the electrolyte of electrode and a microporous glass-fiber membrane filter (Whatman, GF/C) was used as the separator.

\section{RESULTS AND DISCUSSION}

Fig. 3 shows the results of FE-SEM analysis of the silicon-carbon-graphene (Si-C-GR) composites prepared by the aerosol process and heat treatment. In all conditions of various silicon particle sizes, the prepared composites were generally spherical, and the graphene completely covered the silicon and carbon. As the particle size of the silicon became smaller, the inside of the composites was densely packed with silicon and carbon: with showing a spherical shape. As the particle size of the silicon in the composite decreased, the number of silicon particles in one droplet increased in the aerosol process, resulting in a densely filled spherical shape. The size of the Si-C-GR composites showed a distribution of 1 to $5 \mu \mathrm{m}$ regardless of the particle size of the silicon as a raw material.

Fig. 4 indicates the average particle size distribution of the prepared Si-C-GR composites, which was measured by selecting 200 representative particles from the FE-SEM analysis. The average particle size and distribution of the Si-C-GR composites showed a no significant change from about 2.2 to $2.9 \mu \mathrm{m}$ and from 1.27 to $1.28 \mu \mathrm{m}$, respectively. From this result, we conducted that the silicon particle size of the raw silicon material did not significantly affect the size of the composites.

Fig. 5 shows the XRD analysis result of the Si-C-GR composite prepared according to the silicon particle size. The peak of the crystal phase of silicon appeared strongly at about $28^{\circ}$, but the crystal phases of graphene and carbon were not confirmed. In general, the crystalline phase of carbon and graphene appears widely at around $25^{\circ}$, but the crystalline phase of carbon and graphene did not appear to be relatively lower than the crystalline phase of silicon (Fu et al., 2013). In the case of the composite using $50 \mathrm{~nm}$ and $100 \mathrm{~nm}$ commercial silicon, it was confirmed that the crystal phase of silicon was stronger than that of the composites using silicon sludge. 

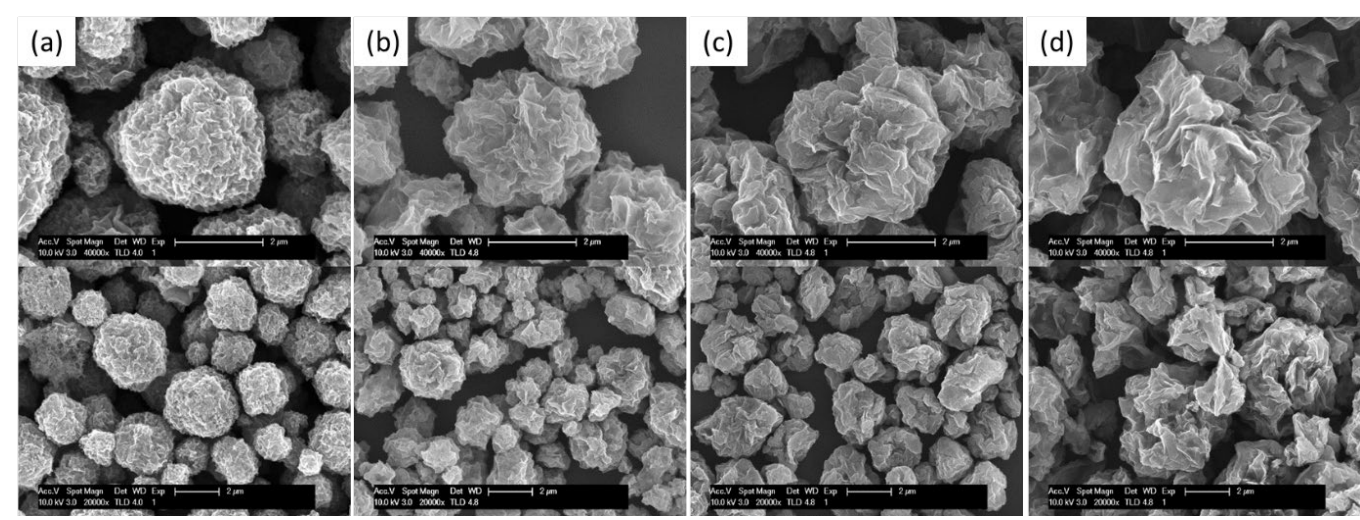

Fig. 3. FE-SEM images of the Si-C-GR composites prepared at different Si sizes of (a) $50 \mathrm{~nm}$, (b) $100 \mathrm{~nm}$, (c) $200 \mathrm{~nm}$ and (d) $1 \mu \mathrm{m}$ (@ Si: 0.3 wt\%, Glucose: 0.2 wt\%, GO: 0.2 wt\%).
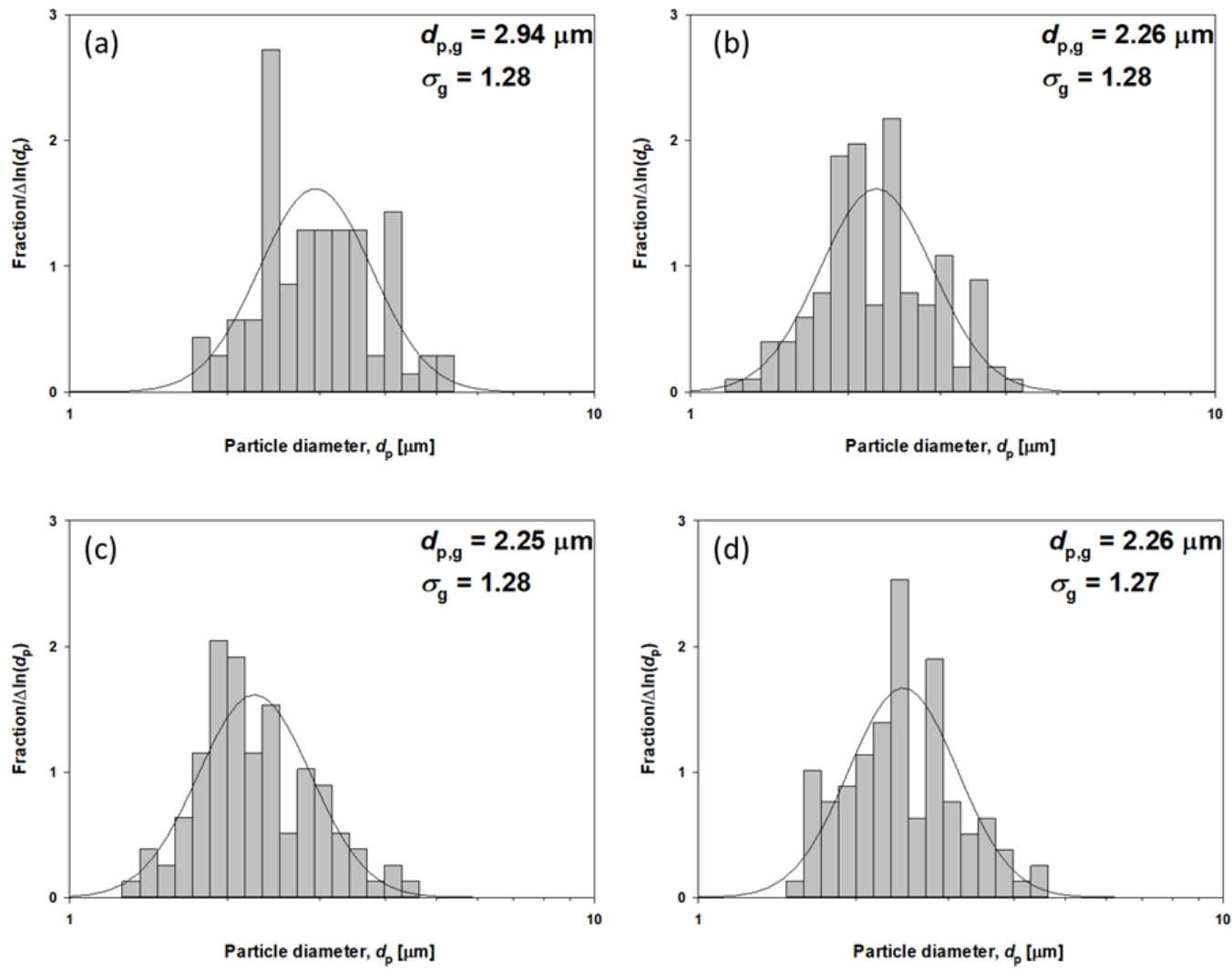

Fig. 4. Particle size distributions of the Si-C-GR composites prepared at different Si sizes of (a) $50 \mathrm{~nm}$, (b) $100 \mathrm{~nm}$, (c) $200 \mathrm{~nm}$ and (d) $1 \mu \mathrm{m}$ (@ Si: 0.3 wt\%, Glucose: 0.2 wt\%, GO: 0.2 wt\%).

Raman analysis results of Si-C-GR composites prepared according to the size of silicon particles are shown in Fig. 6 . The results confirmed that the Si peak appeared at about $520 \mathrm{~cm}^{-1}$, and the $D$ and $G$ peaks corresponded to carbon and graphene at $1350 \mathrm{~cm}^{-1}$ and $1600 \mathrm{~cm}^{-1}$, respectively. The $D$ peak indicated defects from carbon and graphene, and the $G$ peak indicated a $\mathrm{sp}^{2}$ double bond of carbon and graphene (Wang et al., 2016). The existence of carbon and graphene was identified through the Raman results.

Fig. 7 shows the results of the electrochemical characteristics of the prepared Si-C-GR composites according to the silicon particle size as anode materials for LIBs. The initial capacitance of the Si-C-GR composites using silicon particles of $50 \mathrm{~nm}, 100 \mathrm{~nm}, 200 \mathrm{~nm}$, and $1 \mu \mathrm{m}$ was about 1050, 800,800 , and $950 \mathrm{mAh} \mathrm{g}^{-1}$, respectively. It showed a lower value than the initial capacity using pure silicon of $100 \mathrm{~nm}$. On the other hand, when only silicon particles of $100 \mathrm{~nm}$ were used, the 


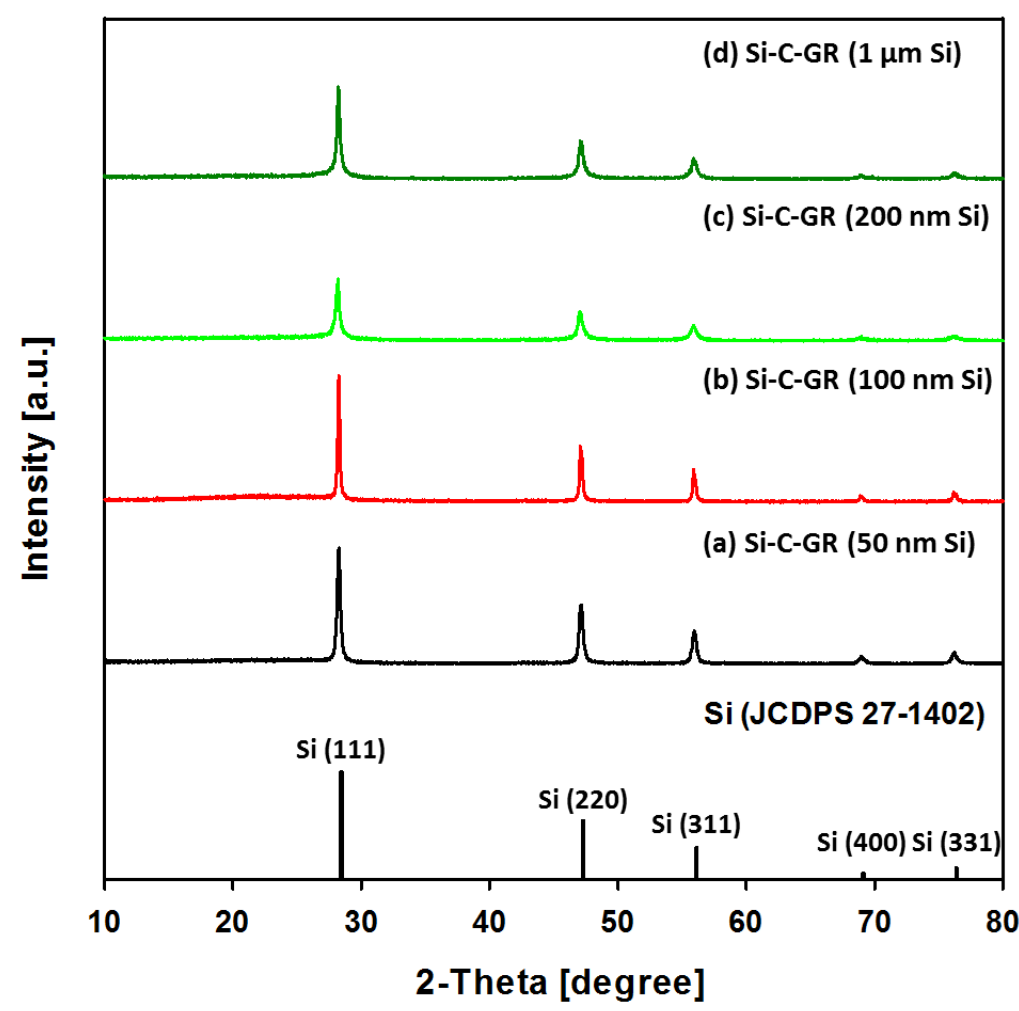

Fig. 5. XRD of the Si-C-GR composites prepared at different Si sizes of (a) $50 \mathrm{~nm}$, (b) $100 \mathrm{~nm}$, (c) $200 \mathrm{~nm}$ and (d) $1 \mu \mathrm{m}$ (@ Si: 0.3 wt\%, Glucose: $0.2 \mathrm{wt} \%, \mathrm{GO}: 0.2 \mathrm{wt} \%$ ).

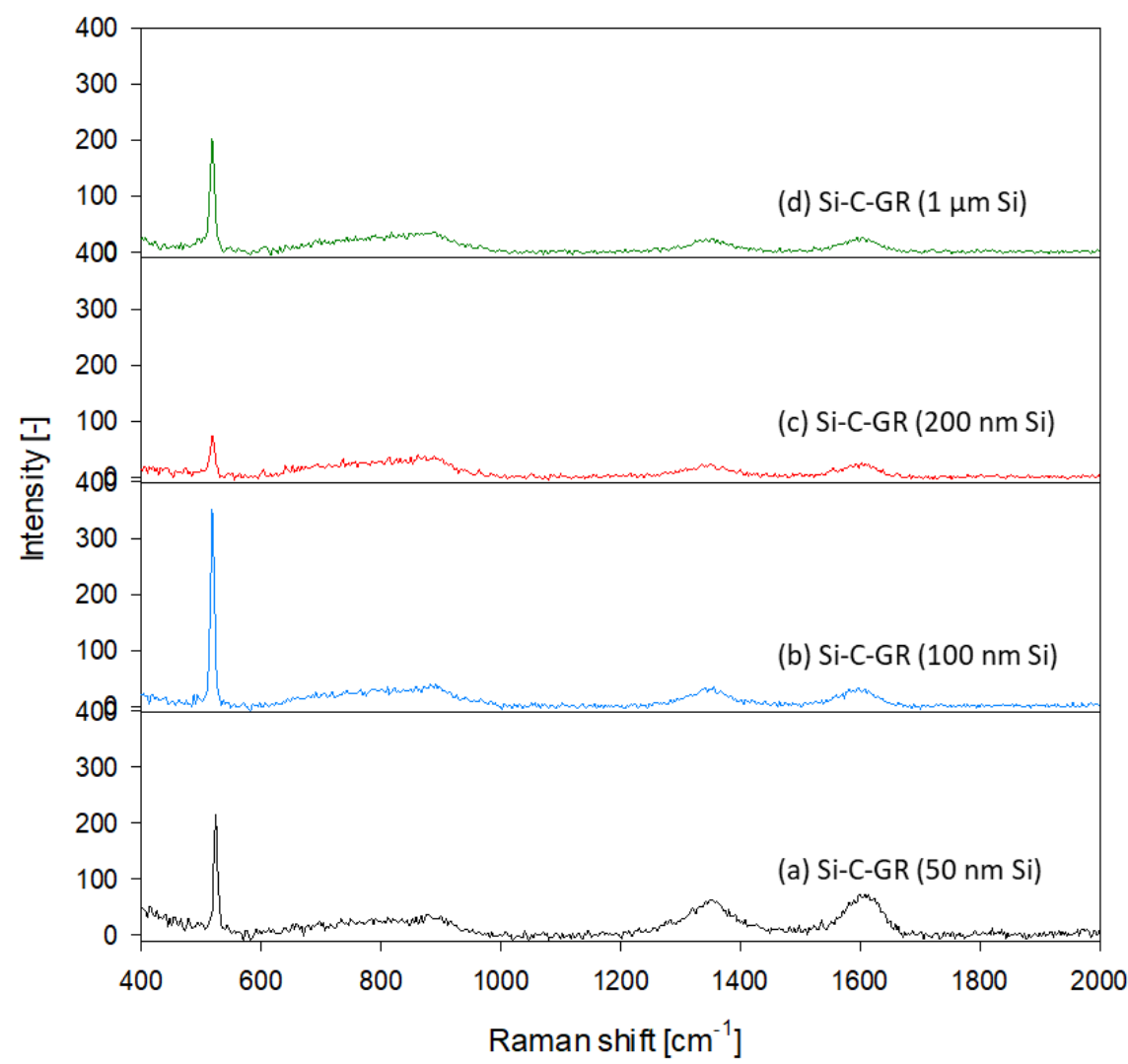

Fig. 6. Raman of the Si-C-GR composites prepared at different Si sizes of (a) $50 \mathrm{~nm}$, (b) $100 \mathrm{~nm}$, (c) $200 \mathrm{~nm}$ and (d) $1 \mu \mathrm{m}$ (@ Si: $0.3 \mathrm{wt} \%$, Glucose: $0.2 \mathrm{wt} \%, \mathrm{GO}: 0.2 \mathrm{wt} \%$ ). 

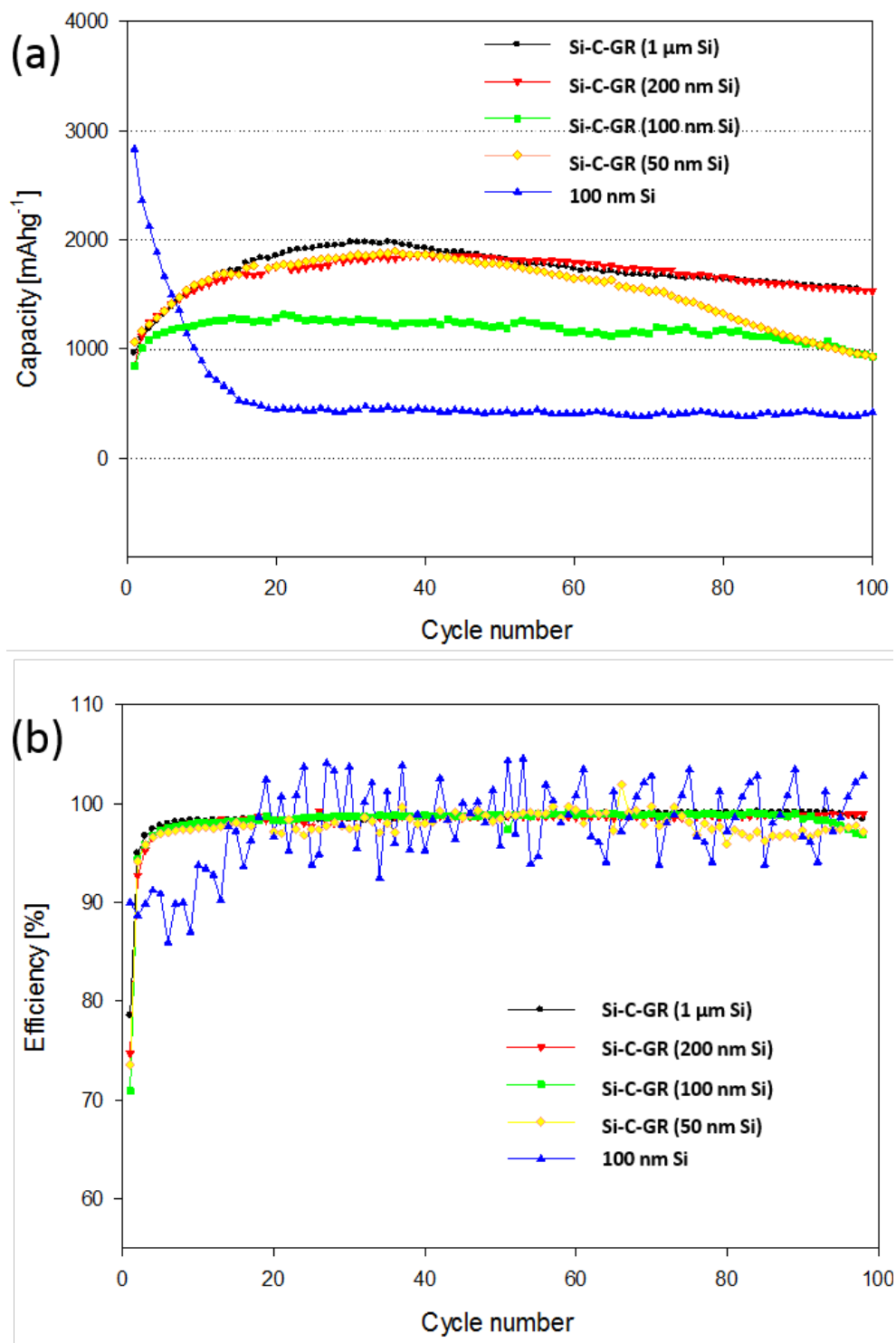

Fig. 7. (a) Cycle performance of Si-C-GR composite electrodes for the 100 cycles and (b) coulombic efficiency of Si-C-GR composite electrodes at different Si sizes in the composites.

initial value was as high as $2800 \mathrm{mAh} \mathrm{g}^{-1}$, but as charging and discharging proceeded, the capacity value rapidly dropped to $500 \mathrm{mAh} \mathrm{g}^{-1}$ after 20 cycles. When only silicon particles were used, we considered that high packing in the solid state prevented the movement of the electrolyte, and large volume change of silicon during charging and discharging could not be accommodated, resulting in low cycle stability.

In contrast, the prepared composites showed capacities of 932, 930, 1532, and $1546 \mathrm{mAh} \mathrm{g}^{-1}$ during the 100 cycle test of charge and discharge, in the order of Si-C-GR composites using silicon particles of $50 \mathrm{~nm}, 100 \mathrm{~nm}, 200 \mathrm{~nm}$, and $1 \mu \mathrm{m}$. This result revealed a superior capacity over pure silicon of $100 \mathrm{~nm}$ (Fig. 7(a)). We considered that carbon double-coated silicon composite structure could overcome the volume expansion of silicon during charge/discharge, thereby maintaining the capacitance of the composite relatively well (Lee et al., 2017; Cai et al., 2017). In particular, the conductivity was improved because of the double-coated silicon with carbon and graphene, and its structure prevented the fracture of the silicon and the formation of an unstable solid electrolyte layer (SEI) (Wang et al., 2016).

As a result of the electrochemical characteristic evaluation of the composites during 100 cycles of charging/discharging, we found that the electrode made of the composite containing $200 \mathrm{~nm}$ of silicon or more was maintained at $1500 \mathrm{mAh} \mathrm{g}^{-1}$ or more. The results also confirmed that the 
composite containing silicon with a particle size of $100 \mathrm{~nm}$ exhibited a value of $1000 \mathrm{mAh} \mathrm{g}^{-1}$ or less. These results showed results similar to previous studies using silicon particles with particle sizes of $100 \mathrm{~nm}$ and $1 \mu \mathrm{m}$ (Luo et al., 2012; Kim et al., 2018b). At a constant weight concentration of silicon, the number of silicon particles of $100 \mathrm{~nm}$ or less in the composites was higher than that of $200 \mathrm{~nm}$ or more. In case of silicon particles of $100 \mathrm{~nm}$ or less, the amount of SEI formed on the entire particle surface during charging and discharging was relatively increased and the resistance of the particle surface was increased to decrease the charge transfer. In the result of the coulombic efficiency analysis, the prepared Si-C-GR composites were maintained at about $95 \%$ or more for 100 cycles under all conditions. The Si-C-GR composites containing silicon particles of $100 \mathrm{~nm}$ or less showed a tendency to slightly decrease in the coulombic efficiency at 100 cycles. In contrast to this, the composite containing silicon with a particle size of $200 \mathrm{~nm}$ or more consistently exhibited excellent cycling performance and stability of more than $99 \%$ (Fig. 7(b)). The composites of double carbon layer manufactured by the aerosol process were able to show excellent performance in the LIB characteristic evaluation. This excellent result was originated in controlling the shape of the composite due to the aerosol process.

\section{CONCLUSIONS}

Silicon-carbon-graphene (Si-C-GR) composites were prepared from a colloidal solution of various sizes of silicon ( $50 \mathrm{~nm}, 100 \mathrm{~nm}, 200 \mathrm{~nm}, 1 \mu \mathrm{m})$, glucose, and graphene oxide for anode materials of high-capacity LIBs. The Si-C-GR composites were fabricated using a facile aerosol process followed by heat-treatment. This aerosol process showed excellent results by controlling the shape of the composite that can give excellent performance in the LIB characteristic evaluation. The composites were generally in the shape of a crumpled ball with an average particle size of 2.2 to $2.9 \mu \mathrm{m}$ regardless of the size change of the silicon particles, and graphene and carbon completely covered the silicon. The silicon, carbon and graphene present in the composite were confirmed through XRD and Raman analysis. The prepared Si-C-GR composites accommodated the volume expansion of silicon during charge/discharge due to the double coating of carbon and graphene within the composite and effectively prevented direct contact with the electrolyte, resulting in excellent cycling performance and stability. The composites with silicon particles larger than $200 \mathrm{~nm}$ exhibited higher capacity and coulombic efficiency performance as LIB anodes than silicon particles smaller than $100 \mathrm{~nm}$, which were about $1500 \mathrm{mAh} \mathrm{g}^{-1}$ at 100 cycles in capacity and $99 \%$ in coulombic efficiency. From the results of this study, we confirmed that Si-C-GR composites with silicon particles with a particle size in the range of $200 \mathrm{~nm}$ to $1 \mu \mathrm{m}$ possess excellent electrochemical properties, and are expected to be widely used as anode materials for high-capacity lithium-ion secondary batteries.

\section{ACKNOWLEDGMENTS}

This research was supported by the Basic Research Project of the Korea Institute of Geoscience and Mineral Resources, funded by the Ministry of Science and ICT.

\section{REFERENCES}

Ashuri, M., He, Q., Shaw, L.L. (2016). Silicon as a potential anode material for Li-ion batteries: Where size, geometry and structure matter. Nanoscale 8, 74-103. https://doi.org/10.1039/C5 NR05116A

Bao, Z.H., Weatherspoon, M.R., Shian, S., Cai, Y., Graham, P.D., Allan, S.M., Ahmad, G., Dickerson, M.B., Church, B.C., Kang, Z., Abernathy III, H.W., Summers, C.J., Liu, M., Sandhage, K.H. (2007). Chemical reduction of three-dimensional silica micro-assemblies into microporous silicon replicas. Nature 446, 172-175. https://doi.org/10.1038/nature05570

Beaulieu, L.Y., Eberman, K.W., Turner, R.L., Krause, L.J., Dahn, J.R. (2001). Colossal reversible volume changes in lithium alloys. Electrochem. Solid-State Lett. 4, A137-A140. https://doi.org/ $10.1149 / 1.1388178$ 
Cai, H., Han, K., Jiang, H., Wang, J., Liu, H. (2017). Self-standing silicon-carbon nanotube/graphene by a scalable in situ approach from low-cost Al-Si alloy powder for lithium ion batteries. J. Phys. Chem. Solids 109, 9-17. https://doi.org/10.1016/j.jpcs.2017.05.009

Chan, C.K., Patel, R.N., O’Connell, M.J., Korgel, B.A., Cui, Y. (2010). Solution grown silicon nanowires for lithium-ion battery anodes. ACS Nano 4, 1443-1450. https://doi.org/10.1021/nn901409q

Cote, L.J., Silva, R.C., Huang, J. (2009). Flash reduction and patterning of graphite oxide and its polymer composite. J. Am. Chem. Soc. 131, 11027-11032. https://doi.org/10.1021/ja902348k

Cui, L.F., Yang, Y., Hsu, C.M., Cui, Y. (2009). Carbon-silicon core-shell nanowires as high capacity electrode for lithium ion batteries. Nano Lett. 9, 3370-3374. https://doi.org/10.1021/nl901670t

Fang, M., Wang, Z., Chen, X., Guan, S. (2018). Sponge-like reduced graphene oxide/silicon/carbon nanotube composites for lithium ion batteries. Appl. Surf. Sci. 436, 345-353. https://doi.org/ 10.1016/j.apsusc.2017.11.070

Fu, C., Zhao, G., Zhang, H., Li, S. (2013). Evaluation and characterization of reduced graphene oxide nanosheets as anode materials for lithium-ion batteries. Int. J. Electrochem. Sci. 8, 62696280.

Jang, H.D., Kim, S.K., Chang, H., Choi, J.W., Luo, J., Huang, J. (2013). One-step synthesis of Ptnanoparticles-laden graphene crumples by aerosol spray pyrolysis and evaluation of their electrocatalytic activity. Aerosol Sci. Technol. 47, 93-98. https://doi.org/10.1080/02786826.2 012.728302

Kang, K.Y., Shin, D.O., Lee, Y.G., Kim, K.M. (2013). Lithium battery anode properties of ball-milled graphite-silicon composites. Korean Chem. Eng. Res. 51, 411-417. https://doi.org/10.9713/kce r.2013.51.4.411

Kasavajjula, U., Wang, C., Appleby, A.J. (2007). Nano-and bulk-silicon-based insertion anodes for lithium-ion secondary cells. J. Power Sources 163, 1003-1039. https://doi.org/10.1016/j.jpows our.2006.09.084

Kim, C.M., Kim, S.K., Chang, H., Kim, D.S., Jang, H.D. (2018a). Synthesis of Si-CNT-C composites and their application to lithium ion battery. Korean Chem. Eng. Res. 56, 42-48. https://doi.org/ 10.9713/kcer.2018.56.1.42

Kim, S.K., Chang, H., Kim, C.M., Yoo, H., Kim, H., Jang, H.D. (2018b). Fabrication of ternary siliconcarbon nanotubes-graphene composites by Co-assembly in evaporating droplets for enhanced electrochemical energy storage. J. Alloys Compd. 751, 43-48. https://doi.org/10.1016/j.jallco m.2018.04.071

Kim, M.K., Shin, W.H., Jeong, H.M. (2019). Protective carbon-coated silicon nanoparticles with graphene buffer layers for high performance anodes in lithium-ion batteries. Appl. Surf. Sci. 467-468, 926-931. https://doi.org/10.1016/j.apsusc.2018.10.253

Lee, B., Liu, T., Kim, S.K., Chang, H., Eom, K., Xie, L., Chen, S., Jang, H.D., Lee, S.W. (2017) Submicron silicon encapsulated with graphene and carbon as a scalable anode for lithium-ion batteries. Carbon 119, 438-445. https://doi.org/10.1016/j.carbon.2017.04.065

Luo, J., Zhao, X., Wu, J., Jang, H.D., Kung, H.H., Huang, J. (2012). Crumpled grapheneencapsulated Si nanoparticles for lithium ion battery anodes. J. Phys. Chem. Lett. 3, 18241829. https://doi.org/10.1021/jz3006892

Oumellal, Y., Delpuech, N., Mazouzi, D., Dupre, N., Gaubicher, J., Moreau, P., Soudan, P., Lestriez, B., Guyomard, D. (2011). The Failure mechanism of nano-sized Si-based negative electrodes for lithium ion batteries. J. Mater. Chem. 21, 6201-6208. https://doi.org/10.1039/C1JM10213C

Park, M.H., Kim, M.G., Joo, J., Kim, K., Kim, J., Ahn, S., Cui, Y., Cho, J. (2009). Silicon nanotube battery anodes. Nano Lett. 9, 3844-3847. https://doi.org/10.1021/nl902058c

Selis L.A., Seminario, J.M. (2018). Dendrite formation in silicon anodes of lithium-ion batteries. RSC Adv. 8, 5255-5267. https://doi.org/10.1039/C7RA12690E

Szczech, J.R., Jin, S. (2011). Nanostructured silicon for high capacity lithium battery anodes. Energy Environ. Sci. 4, 56-72. https://doi.org/10.1039/COEE00281J

Tarascon, J.M., Armand, M. (2001). Issues and challenges facing rechargeable lithium batteries. Nature 414, 359-367. https://doi.org/10.1038/35104644

Wang, J., Liu, D.H., Wang, Y.Y., Hou, B.H., Zhang, J.P., Wang, R.S., Wu, X.L. (2016). Dual-carbon enhanced silicon-based composite as superior anode material for lithium ion batteries. J. Power Sources 307, 738-745. https://doi.org/10.1016/j.jpowsour.2016.01.040

Wang, X., Li, G., Hassan, F.M., Li, M., Feng, K., Xiao, X., Chen, Z. (2015). Building sponge-like robust 
architectures of CNT-graphene-Si composites with enhanced rate and cycling performance for lithium-ion batteries. J. Mater. Chem. A 3, 3962-3967. https://doi.org/10.1039/C4TA06249C

Xiao, J., Xu, W., Wang, D., Choi, D., Wang, W., Li, X., Graff, G.L., Zhang, J.G. (2010). Stabilization of silicon anode for li-ion batteries. J. Electrochem. Soc. 157, A1047-A105. https://doi.org/10. $1149 / 1.3464767$

Yao, Y., McDowell, M.T., Ryu, I., Wu, H., Liu, N.A., Hu, L.B., Nix, W.D., Cui, Y. (2011). Interconnected silicon hollow nanospheres for lithium-ion battery anodes with long cycle life. Nano Lett. 11, 2949-2954. https://doi.org/10.1021/nl201470j

Yen, J.P., Chang, C.C., Lin, Y.R., Shen, S.T., Hong, J.L. (2014). Sputtered copper coating on silicon/graphite composite anode for lithium ion batteries. J. Alloys Compd. 598, 184-190. https://doi.org/10.1016/j.jallcom.2014.01.230

Zhang, F., Yang, X., Xie, Y., Yi, N., Huang, Y., Chen, Y. (2015). Pyrolytic carbon-coated Si nanoparticles on elastic graphene framework as anode materials for high-performance lithium-ion batteries. Carbon 82, 161-167. https://doi.org/10.1016/j.carbon.2014.10.046 